\title{
Physiology Under Graduate Student's Perception of Effective Learning Experience: A Feedback Study
}

Afshan Kausar

\author{
Date of Receiving: 5-02-2021 \\ Date of Review: 9-02-2021 \\ Date of Acceptance: 24-02-2021 \\ DOI:10.47799/pimr.0901.03
}

Afshan Kausar*

*Associate Professor Dept Of Physiology, Jiius Indian Medical Institute Of Medical Science And Research Warudi, Badnapur , Jalna Maharashtra.

Corresponding Author: Dr Afshan Kausar Associate Professor Dept Of Physiology, Jiius Indian Medical Institute Of Medical Science And Research Warudi, Badnapur, Jalna Maharashtra. Email Id; dr.afshankausar@gmail.com

\section{ABSTRACT:}

Introduction: The successful teaching program comprises of well planned curriculum along with its effective execution system, with the intention that the students acquire maximum significant knowledge in the available time-span. A teaching method consists of the principles and technique used for instruction. The methodology of teaching a topic will influence the students, in the comprehension of the subject as well as in the management of clinical conditions. The very certain fact is; students are undoubtedly in the best position to comment on the effectiveness of any the teaching and evaluation methods.

\section{Objective:}

To evaluate the different teaching methods practiced in physiology using student's feedback.

\section{Material And Methods:}

A written questionnaire covering topics on various teaching and evaluation methods was used to get feedback from students. Descriptive statistics was used for analysis of data. Frequency was shown as percentage.

Results :

Most of the students (55\%) preferred combination of conventional \& advanced methods to make lectures effective. Practical sessions of clinical examination are most interesting (70\%)

Conclusion:

Students were satisfied with all teaching methods with certain suggestions. Relevant modifications in the curriculum of physiology as well as other medical subjects must be made time to time according to students need.

Key words: physiology, feedback, teaching methods.

\section{INTRODUCTION :}

Medical education is been regarded as one of the most challenging and demanding profession. Recent trends in medical education are shifting gradually from teacher centered to learner centered approaches. Medical students has huge burden of mastering a diverse set of competencies. Furthermore, the important task in medical education is to provide adequate and satisfactory student learning in the specified duration. The key to success of any education system lies in effective and appropriate planning and programming of the curriculum imparting maximum meaningful knowledge to student in due course of time. This goal is accomplished only when satisfactory communication take place between teachers and students.

Physiology is a vast science; need to be taught by using numerous teaching learning techniques like, lecture, tutorial, demonstrations etc. The most expert teachers emerge from years of experience with a variety of teaching methods. ${ }^{(1)}$ Till date the most common methods used for teaching physiology in the lecture classes include, power point presentations and traditional chalk and board method. The inclination has changed from teaching facts, to helping students to learn how to find relevant information, how to assess it, how to organize incongruent information into a cohesive whole. Consequently progressive and slow stepping towards student centered learning is finding support in the physiological sciences. ${ }^{(2-5)}$

Teaching and evaluation methods must be assessed at regular intervals, and in view of that, modifications of methodologies have to be initiated. Correspondingly move forward in, further improvement and advancement of current undergraduate medical teaching. Moreover, upgrading the teaching system exclusively based on students requirement. 
Course assessment instruments for example, feedback help the teachers to discover the strength and limitations of their teaching and evaluation methods. ${ }^{(6-7)}$ Hence it is important for the faculties to obtain feedback, for developing teaching and evaluation strategies to meet the needs of their students. The students certainly are in the best position to comment on the efficacy of any education system and they may be considered as the excellent judges to assess the teaching and evaluation methods. at present, student's feedback represents the primary means used by most programmers to evaluate their methodology. ${ }^{(8)}$ Feedback from students is the best method to bridge the communication gap between teachers and students. ${ }^{(9)}$ Indeed it is an important tool for improving the quality of teaching.

Although various verbal and non-verbal feedback is communicated to the teachers, but the work is not published from our institute. This encouraged us to commence this study and move a step ahead in improving student and teacher awareness of this information and make the teaching and evaluation more effective. To accomplish this goal, feedback on teaching and evaluation methods in the subject of physiology was obtained from the first MBBS students after they finished first professional undergraduate medical examination in our institution.

\section{Aim \& objectives:}

To assess the various teaching/learning methods practiced in physiology by means of students' feedback.

\section{Materials and methods:}

Study was conducted on 100 medical students of first MBBS at department of physiology JIIUS IIMSR Medical College Badnapur Jalna Maharashtra. The details of the study and objectives were explained to enrolled students. A questionnaire was designed and prevalidated based on the teaching methods practiced in the department of physiology, they were supposed to fill the questionnaire consisted of questions regarding:

1. Lectures

2. Tutorials

3. Horizontal integrated seminar

4. Subject seminar

5. Practical

6. Other related questions

7. Put up the suggestions

The study was approved by institutional ethical committee.

\section{Statistical analysis:}

Descriptive statistics was used for analysis of data. Frequency was shown as percentage.

\section{Result :}

Lectures: The best method (55\%) of lecture by student feedback is the use of LCD projector along with chalk \& board, blend is best for comprehension.23\%, student felt the use of power point with LCD projector is better since it makes topic interesting \& effective. Whereas $22 \%$ said that the conventional chalk $\&$ board is the better method because it allows time to understand \& register diagrams. No one is in favor of using OHP.(fig 1)When asked about lecture strategy most of the student $(84 \%)$ said one system at a time is better than two system (15\%),three system(1\%) . (fig 2)

92\% (fig 3) said that tutorials are very helpful small group method, according to them it not only facilitates understanding but also better communication with teacher is possible. Subsequently doubts can be comfortably asked and solved with healthier discussion on topic. While $8 \%$ felt that these are not useful because many a times there is repetitions of topics. Similarly subject seminar helps in learning (60\%) but not helpful for some (40\%) could be because not all students prepared for it. On the contrary horizontal integrated seminar provide in depth learning of topic in all subject simultaneously, and are much helpful (96\%) but for selected topics.

In practical, clinical examination was found to be the most interesting session (70\%) (fig 4) for students. They told, it is the only session in which they learn how to examine patient and become skilled at clinical techniques as a physician. While experimental and hematology practical were25\% \&5\% respectively, as in experimental sessions no practical work is done which made it equivalent to theoretical session, thus it becomes the least interesting session among students. Although they felt, it is the easiest session to understand.

$94 \%$ (fig 5) students felt that revision practicals are needed since with repetition they can practice more and develop perfect skills, as well as understanding \& remembering things becomes easy for them. Only $6 \%$ felt that revision practicals should be kept before examinations \& not frequently. Students feedback about physiology as a subject showed, 48 $\%$ ( fig 6) said that the subject is difficult \& $52 \%$ felt that the subject is not difficult however is conceptual, vast \& volatile. Increasing frequency of examinations smoothen the progress of learning was felt by $72 \%$ students(fig 7 ) , while $28 \%$ felt that frequent examination provides less time to prepare, hence does not affect learning much . 82\% students (fig 8 ) were satisfied with pattern of internal assessment but $18 \%$ felt timing of first term exam is late, it must be early. 


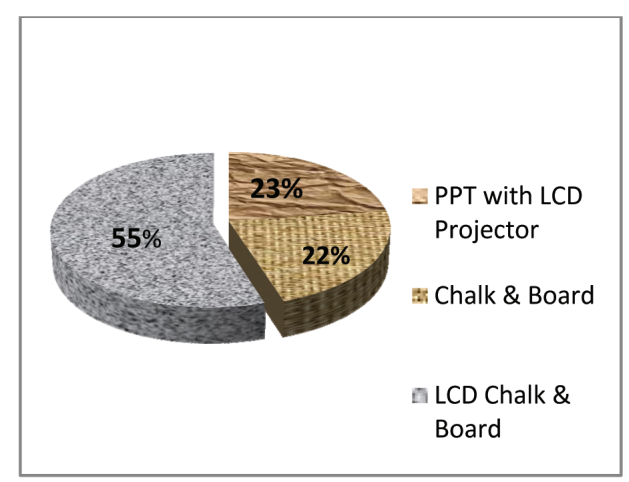

FIG 1; lecture technique

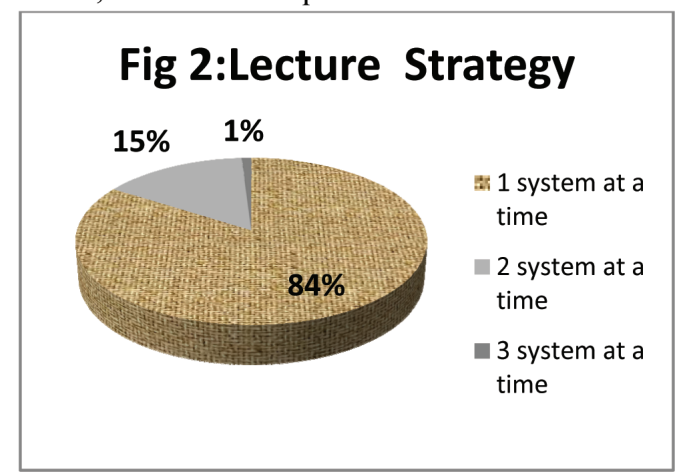

Fig 2; Lecture Strategy

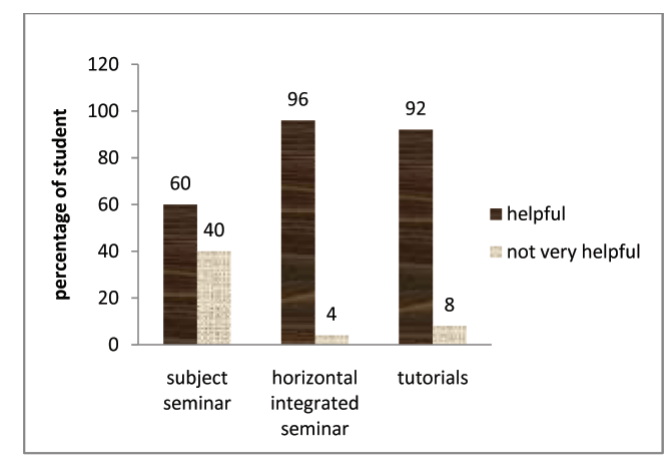

Fig 3;subject seminar ,horizontal integrated seminar, tutorials

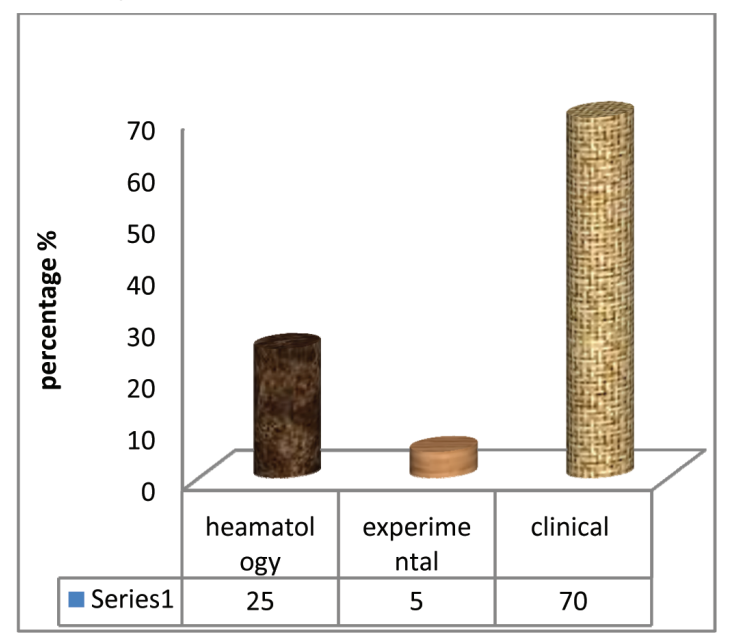

Fig 4; Most interesting practical session
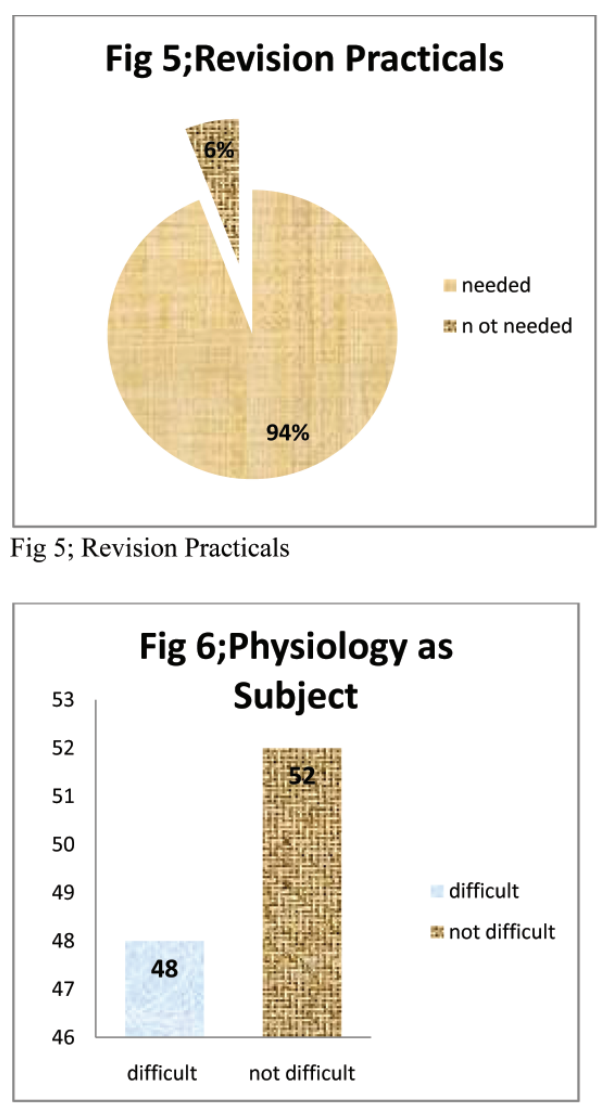

Fig6; Physiology As A Subject


Fig8; Pattern Of Internal Assessment 


\section{Discussion:}

The present study was undertaken to evaluate different existing teaching methods in physiology. The results of the present study reveal that students are satisfied with the present teaching methodology. The important suggestion gained was to apply blend of advanced \& conventional methods to create more effective lecture. It was also found that, practical sessions of clinical examination are most interesting and that of experimental are least interesting. Consequently, efforts have to be taken to build these topics more attention-grabbing. Our findings are in consistent with the findings of Sayali et al ${ }^{(10)}$ which showed blended method as best choice. The interactive classes like tutorials, having bilateral communication were more popular amongst the students. Majority of the student of the students considered horizontal integrated and subject seminar are good for understanding. Students commented that these type of student centered activities must be done regularly and more frequently on a variety of applied physiology and clinical physiology topics.

Similar conclusion was given by Muneshwar et al(11) found out that there needs to be a decrease in the generation gap between the students and teachers by organizing frequent group activities and interactive sessions. Comparable result was found in study conducted by Chavda $\mathrm{n}$ et $\mathrm{al}^{(12)}$ this enhances the student's involvement in topic which may improve their performance in examination. ${ }^{(13)}$

Although,Students were pleased with pattern of internal assessment, but had suggested that first internal assessment must be planned at an earlier date. This will help them understand the assessment method, to prepare the subject according to assessment strategy all the way from initial months of course. This will result in building up confidence as well as help in relieving the apprehension of internal assessment at an early stage thus improved and enhanced learning outcomes will be attained.

\section{Conclusion :}

It is need of the hour to know our students requirements. Feedback of Students is must on medical curriculum plan and programming; for example, whether they feel comfortable with the ever growing and expanding medical physiology subject, which need to be taught in narrow frame of time. This study is just a small attempt to gather the opinion of students about teaching methods \& whether any changes can be made to improve it. Feedback has been called the life blood of learning and is thought to be particularly advantageous if granted under conditions that are stress free. One must not forget, frequent feedback may facilitate the teachers to plan, prepare and execute the relevant curriculum of physiology and modify the teaching and evaluation methodologies adopted in their institutions. It is very important to synchronize teaching and evaluation methods according to special requirements of medical students. The suggestions based on this study will be implemented on the next batch of students. This definitely is not a complete picture. Our study does not intend to judge the existing methods.

\section{Acknowledgements:} in the study.

Authors like to thank all students for their participation

\section{REFERENCES}

1. Kalpana Ernest, K.N. Anand, Nalinikanagasabapathy, Sujith J. Chandy, Alice Kuruvilla, And Molly Thomas., Patientoriented Problem Solving (Pops)Approach And Audiovisual Aided(Ava)Lectures In Teaching Pharmacology - Acomparative Study. Indian Journal Ofpharmacology, 30: 97-101,(1998)

2. Mccrone J. Wild Minds: The Dynamics Of The Neural Code. New Scientist. 1997;156:26-30

3. Reese Ac Implication Of Results From Cognitive Science Research For Medical Education. Acad Med 1996 Sep;71(9):988-1001

4. Anderson Mc, Neely Jh Interference And Inhibition In Memory Retrieval Cited In Reese Ac Acad Med 1996 Sep;71(9):988-1001

5. Regehr G, Norman Gr. Issues In Cognitive Psychology: Implications For Professional Education.

6. Ruth, N. (2000) Communicating Student Evaluation Of Teaching Results: Rating Interpretation Guides (Rigs).Assessment \& Evaluation In Higher Education, 25, 121-134.

7. Richardson, B.K. (2004) Feedback. Academic Emergency Medicine, 11, 1-5.

8. Victoroff,, K.Z. \& Hogan, S. (2006) Students' Perceptions Of Effective Learning Experiences In Dental School: A Qualitative Study Using A Critical Incident Technique. Journal Of Dental Education, 70,124-132.

9. Sehgal, R., Dhir, V. \& Sawhney, A. (1998) Teaching Technologies In Gross Anatomy (Abstract). Journal Of The Anatomical Society Of India, 48, 36.).

10. Rautsayali E, Pagaratish B, Dr.Kadam Charulata, Dr Kowale Arun N, Bhutada Tara B,Dr.Aundhkar V. G, Teaching Methods In Physiology: Students' Feedback losr Journal Of Research \& Method In Education: 2014volume 4, Issue 1 Ver. li Pp 63-67 
11. Muneshwar Jn, Mirza Shiraz Baig, Zingade Us, Khan St. A Questionnaire Based Evaluation Of Teaching Methods Amongst Mbbs Student. Int J Med Res Health Sci.2013; 2 (1): 19-22.

12. Nilesh Chavda, Preeti Yadav Second Year Student's Feedback On Teaching Methodology And Evaluation Methods In Pharmacology. National Journal Of Physiology, Pharmacy And Pharmachology. 2011; 1: 23-31

13. Kaufman M, Mann V. Achievements Of Students In Conventional And Problem Based Learning (Pbl) Curriculum. Adv Health Sci Edu 1999; 4: 245-60.

How to cite this article : Kausar A. Physiology under Graduate Student's Perception of Effective Learning Experience: A Feedback Study. Perspectives in Medical Research 2021; 9 (1):12-16

DOI:10.47799/pimr.0901.03

Sources of Support: Nil, Conflict of interest: None declared 